Material Properties

\title{
Fabrication of a novel hierarchical fibrous scaffold for breast cancer cell culture
}

\author{
Honglin Luo ${ }^{\mathrm{a}, \mathrm{b}}$, Teng Cui ${ }^{\mathrm{a}}$, Deqiang Gan ${ }^{\mathrm{a}}$, Miguel Gama ${ }^{\mathrm{c}}$, Quanchao Zhang ${ }^{\mathrm{a}, * *}$, Yizao Wan ${ }^{\mathrm{a}, \mathrm{b}, *}$ \\ ${ }^{a}$ Institute of Advanced Materials, East China Jiaotong University, Nanchang, 330013, China \\ ${ }^{\mathrm{b}}$ School of Materials Science and Engineering, Tianjin University, Tianjin, 300072, China \\ ${ }^{\mathrm{c}}$ Centro de Engenharia Biológica, Universidade Do Minho, Campus de Gualtar, P 4715-057, Braga, Portugal
}

\section{A R T I C L E I N F O}

\section{Keywords:}

Cellulose fiber

Hierarchical structure

Cancer cell

In vitro culture

\begin{abstract}
A B S T R A C T
Scaffolds combining nano- and submicro-fibers closely mimicking extracellular matrix (ECM) have been poorly exploited for in vitro cancer cell culture. Herein, a combined electrospinning and modified in situ biosynthesis method has been developed to fabricate a novel scaffold consisting of bacterial cellulose (BC) nanofibers and electrospun cellulose acetate (CA) submicrofibers to mimic the fibrillar structure of natural ECM. The CA/BC nano/submicrofibrous scaffold was characterized by scanning electron microscopy (SEM), mechanical strength tests, porosity measurements, and cell studies using the MCF-7 breast cancer cells. In addition, the sensitivity of the cancer cells seeded in the CA/BC nano/submicrofibrous scaffold to an anticancer drug was assessed. It was found that the CA/BC scaffold exhibited an interconnected porous structure in which BC nanofibers penetrated into the submicrofibrous CA scaffold. Such sophisticated structure was responsible for the improved mechanical properties of CA/BC scaffold over the ones obtained using a single kind of fibers. More importantly, the CA/BC scaffold showed improved cell adhesion, migration, and proliferation over single BC or CA scaffold. Finally, cells grown on CA/BC scaffold exhibited a greater doxorubicin resistance than those on single CA or BC scaffold. The results suggest that the $\mathrm{CA} / \mathrm{BC}$ nano/submicrofibrous scaffold has potential for application in in vitro tumor model for the study of cancer progression and drug screening.
\end{abstract}

\section{Introduction}

Cancer affects millions of people worldwide and has become a leading cause of death. Therefore, investigation on the formation, invasion, metastasis of malignant tumor is of critical importance. In this context, in vitro cancer models (analogous to scaffolds in tissue engineering) that mimic the microenvironment where the cancerous cells reside and the tumor develops are highly demanded. Such in vitro cancer models have been proven effective in studying cancer pathogenesis and development, anti-cancer mechanism, and drug testing [1-4]. So far, numerous materials including gelatin, carbon nanotube, collagen, fibrin, poly(lactic acid), poly(glycolic acid), poly(lactic-coglycolic acid), poly ( $\varepsilon$-caprolactone), and others have been used to construct in vitro cancer models [5-7]. In our previous studies, bacterial cellulose (BC) was also used in light of its 3D network structure and, in particular, its nano-scaled fiber diameter which is the lower limit of natural ECM fibers $[8,9]$. This is desirable and necessary since both chemical composition and scaffold architecture are important parameters for in vitro cancer models. In tissue engineering, scaffolds that bear structure similar to natural extracellular matrix (ECM) are highly desirable since they can promote cell attachment and proliferation and finally to promote new ECM growth [10]. In this context, fibrous scaffolds that mimic natural tissues are widely studied due to their ability to manipulate cell fate by providing topographical cues $[11,12]$. In recent years, many researchers have agreed that it is extremely important to take into account of the multiscale organization of the natural ECM, which is composed of fibers ranging from dozens to hundreds of nanometers. Therefore, in designing new scaffolds for tissue engineering, it is important to endow them with hierarchical structure. Previously, multilayered hierarchical scaffolds were reported [13-15]. However, some tissues such as cornea have an integrated nano-micro-fibrous structure. Although many previous studies have demonstrated that scaffolds for tissue engineering could be used for tumor engineering [5,16-18], no report dealing with the hierarchical interpenetrated fibrous scaffolds for tumor engineering can be found in literature.

\footnotetext{
* Corresponding author.Institute of Advanced Materials, East China Jiaotong University, Nanchang, 330013, China.

** Corresponding author.

E-mail addresses: zhangquanchao2006@126.com (Q. Zhang), yzwantju@126.com (Y. Wan).
} 
In this work, we have prepared a novel hierarchical fibrous scaffold with nano- and submicro-fibers by combining BC nanofibers with a diameter smaller than $100 \mathrm{~nm}$ with submicrofibers of electrospun cellulose acetate (CA) with a diameter of a few hundreds of nanometers for potential applications in tumor engineering (as an in vitro cancer model). The CA submicrofibrous scaffold was fabricated by electrospinning. The $\mathrm{BC}$ nanofibers were then totally impregnated into the submicrofibrous CA scaffold using a modified in situ biosynthesis process [19-21]. The resultant hierarchical fibrous CA/BC scaffold with interpenetrated nano ( $c a .49 \mathrm{~nm}$ ) and submicron $(c a .780 \mathrm{~nm})$ fibrous structure was seeded with MCF-7 breast cancer cells to assess the suitability of the hierarchical fibrous scaffold for potential application as tumor engineering scaffolds. The purpose of this work was thus to prepare and characterize the novel scaffold consisting of nanofibrous BC and submicrofibrous CA and test the growth, adhesion, and proliferation of the MCF-7 cells on the scaffold. As control, single BC nanofibrous scaffold and electrospun CA submicrofibrous scaffold were also prepared and characterized. In addition, the antiproliferative effect of a model anticancer drug (doxorubicin) on the cancer cells seeded on various scaffolds was tested.

\section{Materials and methods}

\subsection{Preparation of submicrofibrous CA scaffold by electrospinning}

The submicrofibrous CA scaffold was prepared by electrospinning at $40 \%$ relative humidity and room temperature. The concentration of CA solution was kept at $15 \mathrm{wt} \%$ which was obtained by dissolving $1.5 \mathrm{~g}$ of CA $\left(\mathrm{Mn}=4.0 \times 10^{4} \mathrm{~g} \mathrm{~mol}^{-1}\right.$, supplied by Shanghai Aladdin Bio-Chem Technology Co. Ltd., Shanghai, China) into $10 \mathrm{~mL}$ of acetone/acetic acid mixture at a volume ratio of $1: 1$ under constant stirring. The solution was fed into a plastic syringe $(10 \mathrm{~mL})$ with a metal needle tip which was driven by a syringe pump. The applied voltage was $10 \mathrm{kV}$, the flow rate was $5 \mathrm{~mL} / \mathrm{h}$, and the tip-to-collector distance was $15 \mathrm{~cm}$. The obtained CA scaffold was dried in vacuum oven at $80^{\circ} \mathrm{C}$ for $24 \mathrm{~h}$.

\subsection{Preparation of nano-submicrofibrous $C A / B C$ scaffold}

To incorporate BC nanofibers into submicrofibrous CA scaffold, a modified in situ biosynthesis method was applied [19-21] using the bacterial strain Komagataeibacter xylinus X-2 and a culture medium composed of $2.5 \%(\mathrm{w} / \mathrm{v})$ glucose, $0.75 \%(\mathrm{w} / \mathrm{v})$ yeast extract, $1 \%(\mathrm{w} / \mathrm{v})$ tryptone, and $1 \%(\mathrm{w} / \mathrm{v}) \mathrm{Na}_{2} \mathrm{HPO}_{4}$ [22-25]. Firstly, a BC pellicle with a thickness of $3 \mathrm{~mm}$ was prepared by conventional static culture method and used as the substrate on which submicrofibrous scaffold was placed. Secondly, the atomized culture medium was deposited onto the CA scaffold followed by in situ BC growth within the CA scaffold. After $\mathrm{BC}$ growth, the atomizing and growing was repeated up to the fifth cycle, each one taking around $6 \mathrm{~h}$. Finally, the harvested CA/BC scaffold (after removing BC substrate) was purified by soaking in deionized water at $90^{\circ} \mathrm{C}$ for $2 \mathrm{~h}$, boiling in a $0.5 \mathrm{M} \mathrm{NaOH}$ solution for $15 \mathrm{~min}$ to remove residual bacteria within $\mathrm{BC}$ network, and thorough washing with abundant deionized water. The CA/BC hydrogel was then immersed in tertiary butanol which was renewed 3 to 4 times to remove deionized water followed by freeze drying at $-20{ }^{\circ} \mathrm{C}$ for $12 \mathrm{~h}$, and finally lyophilized at $-50^{\circ} \mathrm{C}$ for $24 \mathrm{~h}$, yielding CA/BC scaffold. The resultant CA/BC scaffold had a BC weight content of $c a .12 \%$. As control, a bare $\mathrm{BC}$ scaffold was also prepared by the same procedure.

\subsection{Characterization}

Morphology of the scaffolds was investigated using a FEI Nano 430 scanning electron microscope (SEM). The fiber diameter and the average pore sizes were measured and averaged using the Nano Measure1.2 software by randomly selecting at least 100 fiber segments and pores, respectively [21,26,27].
Water contact angles of BC, CA, and BC/CA materials (after pressing at room temperature) were measured with a contact angle meter (Drop Master 300).

Porosity of the scaffolds was measured by the liquid displacement method using ethanol as the medium. The porosity was calculated using Equation (1):

Porosity $(\%)=\frac{\frac{W_{b}-W_{c}-W_{i}}{\rho_{e}}}{\frac{W_{a}-W_{c}}{\rho_{e}}} \times 100 \%$

where $W_{\mathrm{a}}$ represents the weight of the specific gravity bottle filled with ethanol, $W_{\mathrm{b}}$ is the weight of the specific gravity bottle filled with ethanol and scaffold, and $W_{\mathrm{c}}$ denotes the weight of the specific gravity bottle after subtracting the weight of the scaffold from $W_{\mathrm{b}} ; W_{\mathrm{i}}$ is the initial weight of the scaffold and $\rho_{\mathrm{e}}$ denotes the density of ethanol $\left(0.8 \mathrm{~g} \mathrm{~cm}^{-3}\right)$.

Tensile properties were tested using a micro-electromagnetic fatigue testing machine (MUF-1050, Tianjin Care Measure \& Control Co., Ltd., Tianjin, China) and the specimen dimensions were $10 \times 5 \times 2 \mathrm{~mm}^{3}$. The measurement was carried out at a strain rate of $5 \mathrm{~mm} \mathrm{~min}^{-1}$ and repeated at least five times.

\subsection{Cell studies}

\subsubsection{Cell culture and seeding on scaffolds}

The MCF-7 breast cancer cells used in this work were obtained from Shanghai cell bank, Chinese Academy of Sciences. After being passaged to the sixth generation, the MCF-7 cells were cultured in dulbecco's modified eagle medium (DMEM, Hyclone, America) supplemented with $10 \%$ fetal bovine serum (Gibco, South America) in a humidified incubator with $5 \% \mathrm{CO}_{2}$ at $37{ }^{\circ} \mathrm{C}$. The culture medium was renewed every other day.

After sterilization at $121{ }^{\circ} \mathrm{C}$ for $30 \mathrm{~min}$ (LDZX-30KBS, Shen an, China), the scaffolds (with a thickness of about $1 \mathrm{~mm}$ and a diameter of $15 \mathrm{~mm}$ ) were placed into 24 -well culture plates, seeded at a cell density of $1 \times 10^{4}$ cells/well, and then incubated in a $5 \% \mathrm{CO}_{2}$ incubator at $37^{\circ} \mathrm{C}$. The scaffolds were withdrawn at predetermined time points for subsequent characterizations.

\subsubsection{Cell proliferation}

The cell proliferation was evaluated by Cell Counting Kit-8 (CCK8) assay. The sterilized scaffolds were pre-soaked in DMEM for at least $12 \mathrm{~h}$, followed by incubation in 24-well tissue culture plates for 1, 4, and 7 days in a $5 \% \mathrm{CO}_{2}$ incubator at $37^{\circ} \mathrm{C}$. After transferring the scaffolds to new 24-well culture plates, $300 \mu \mathrm{L}$ of medium (containing CCK8 reagent) was added to each well and then incubated in a $5 \% \mathrm{CO}_{2}$ incubator at $37^{\circ} \mathrm{C}$ for $3 \mathrm{~h}$. Afterwards, $100 \mu \mathrm{L}$ of culture medium was transferred to 96 -well plates for the measurement of absorbance at $450 \mathrm{~nm}$ using a microplate reader (iMark, Bio Rad, USA).

\subsubsection{Cell morphology}

After incubation in a $5 \% \mathrm{CO}_{2}$ incubator at $37^{\circ} \mathrm{C}$ for 4 and 7 days, the cell-loaded scaffolds were thoroughly rinsed with phosphate buffered saline (PBS) followed by staining with live staining reagent (Fluorescein diacetate) for $3 \mathrm{~min}$. The stained cultures were observed using a fluorescence microscope (TS2, Nikon, Japan) and confocal laser scanning microscopy (CLSM, TCS SP8, Leica, Germany). The cytoskeletons and nuclei of the MCF-7 cells attached on the scaffolds were stained with rhodamine phalloidin (Molecular Probe, Sigma-Aldrich) and 4',6diamidino-2-phenylindole dihydrochloride (DAPI, Molecular Probe, Sigma-Aldrich), respectively to assess cell clusters and spreading using the fluorescence microscope mentioned above.

For SEM observation, cells (after incubation in a $5 \% \mathrm{CO}_{2}$ incubator at $37^{\circ} \mathrm{C}$ for 4 and 7 days) were fixed with $2.5 \%$ glutaraldehyde solution at $4{ }^{\circ} \mathrm{C}$ for $12 \mathrm{~h}$, and then dehydrated in a graded series of ethanol $(50$, $60,70,80,90,95$, and $100 \%$ ), coated with a layer of gold, and observed 
by SEM (FEI Nano 430).

\subsubsection{Antiproliferative effect of anticancer drugs}

A doxorubicin (DOX) solution was first prepared with deionized water. After cell seeding at a density of $1 \times 10^{5}$ cells/well for $24 \mathrm{~h}$, the culture medium mentioned above was removed and replaced with $5 \mathrm{~mL}$ of drug-containing medium (drug concentration $20 \mathrm{mg} / \mathrm{mL}$ ). $24 \mathrm{~h}$ after drug addition, the cell proliferation CCK8 assay determination was performed as described above.

\subsection{Statistical analysis}

The experimental data obtained from at least three independent experiments was analyzed using an SPSS system. The mean values and standard deviations (SD) were reported and a $p$-value of less than 0.05 was considered statistically significant.

\section{Results and discussion}

\subsection{Characterizations of $C A / B C$ scaffold}

The morphologies of pristine BC nanofibrous scaffold, electrospun CA submicrofibrous scaffold, and CA/BC nano-submicrofibrous scaffold are shown in Fig. 1. Fig. 1a reveals a typical 3D interconnected porous structure with an average fiber diameter of $49.4 \pm 1.2 \mathrm{~nm}$ (inset in Fig. 1a). In the case of electrospun CA submicrofibrous scaffold, a porous structure consisting of larger fibers with an average diameter of $780.4 \pm 10.6 \mathrm{~nm}$ is observed (Fig. $1 \mathrm{~b}$ and inset). As expected, CA/BC nano-submicrofibrous scaffold shows the homogeneous distribution of BC nanofibers and CA submicrofibers both on the surface (Fig. 1c) and in the cross-section (Fig. 1d). In addition, the CA/BC scaffold shows an interpenetrated and entangled structure, which might be beneficial to the improvement of mechanical strength of the CA/BC scaffold. The SEM results confirm that the combined method of in situ biosynthesis and electrospun is an effective approach to fabricate the nano-submicrofibrous scaffold.

Tensile properties of $\mathrm{BC}, \mathrm{CA}$, and $\mathrm{CA} / \mathrm{BC}$ scaffolds are presented in
Table 1

Tensile properties of BC, CA, and CA/BC scaffolds.

\begin{tabular}{llll}
\hline Materials & Tensile strength (MPa) & Tensile modulus (MPa) & Strain at break (\%) \\
\hline BC & $0.64 \pm 0.02$ & $8.30 \pm 0.53$ & $25.7 \pm 0.6$ \\
CA & $0.71 \pm 0.05$ & $10.35 \pm 0.44$ & $16.4 \pm 0.6$ \\
CA/BC & $0.80 \pm 0.01$ & $11.10 \pm 0.51$ & $17.3 \pm 0.7$ \\
\hline
\end{tabular}

Table 1. Interestingly, CA/BC scaffold exhibits a higher tensile strength $(0.80 \pm 0.01 \mathrm{MPa})$ than $\mathrm{BC}(0.64 \pm 0.02 \mathrm{MPa})$ and CA scaffolds $(0.71 \pm 0.05 \mathrm{MPa})$. In addition, $\mathrm{CA} / \mathrm{BC}$ also exhibits a higher tensile modulus $(11.10 \pm 0.51 \mathrm{MPa})$ than $\mathrm{BC}(8.30 \pm 0.53 \mathrm{MPa})$, but similar to that of CA scaffold $(10.35 \pm 0.44 \mathrm{MPa})$. Note that the CA/BC scaffold shows a lower strain at break $(17.3 \pm 0.7 \%)$ than $\mathrm{BC}$ $(25.7 \pm 0.6 \%)$ although it is slightly higher than CA $(16.4 \pm 0.6 \%)$. The improved mechanical strength and modulus are due to the mechanical entanglement between BC nanofibers and CA submicrofibers, as commonly observed for entangled fiber network [28,29].

Porosity is a very important parameter for scaffolds [30]. The porosity values measured in this work are displayed in Fig. 2. Porosities of $\mathrm{BC}, \mathrm{CA}$, and $\mathrm{CA} / \mathrm{BC}$ are $94.55 \pm 1.32 \%, 87.03 \pm 1.63 \%$, and $91.93 \pm 2.17 \%$, respectively. The porosity of CA/BC lies between BC and CA and is larger than $90 \%$, which is a favorable value for cell ingrowth [31]. Fig. 2b-d shows the distribution of pore size of BC, CA, and CA/BC. As expected, BC has small pores ranging from 2 to $32 \mu \mathrm{m}$ with most pores smaller than $10 \mu \mathrm{m}$ (Fig. 2b) and CA exhibits larger pores varying from 10 to $85 \mu \mathrm{m}$ mostly around $40 \mu \mathrm{m}$ (Fig. 2c). It is noted that the pore size of $\mathrm{CA} / \mathrm{BC}$ changes in a wide range of $6-58 \mu \mathrm{m}$ with dominant pores at 6-32 $\mu \mathrm{m}$ (Fig. 2d).

In this work, the contact angles of $\mathrm{BC}$, CA, and CA/BC materials were measured. As shown in Fig. 2e, CA exhibits an average contact angle of $123.6^{\circ}$ while $\mathrm{BC}$ shows a low contact angle of $34.5^{\circ}$. The large value of CA, which was also reported by other researchers [32,33], is due to its acetylation and the low contact angle of $\mathrm{BC}$ is related to the large amount of surface hydroxyl groups on its surface. Interestingly, $\mathrm{CA} / \mathrm{BC}$ shows an average value of $43.4^{\circ}$. The significantly lower value of $\mathrm{CA} / \mathrm{BC}$ than $\mathrm{CA}$ can be explained by the purification of $\mathrm{CA} / \mathrm{BC}$ in
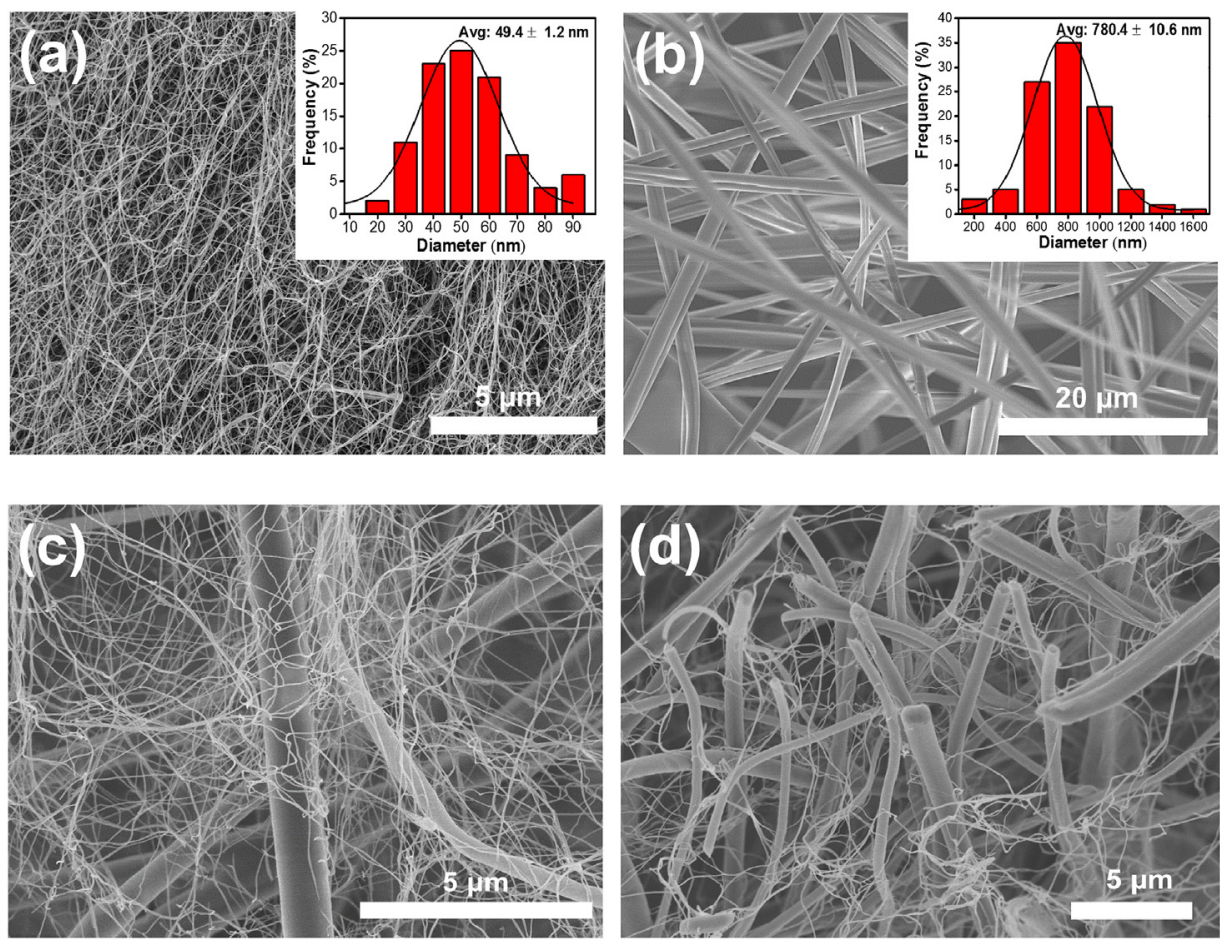

Fig. 1. SEM images of BC (a), CA (b), and CA/BC (c) scaffolds. (d) Cross-sectional morphology of CA/BC scaffold. Insets show fiber diameter distribution. 

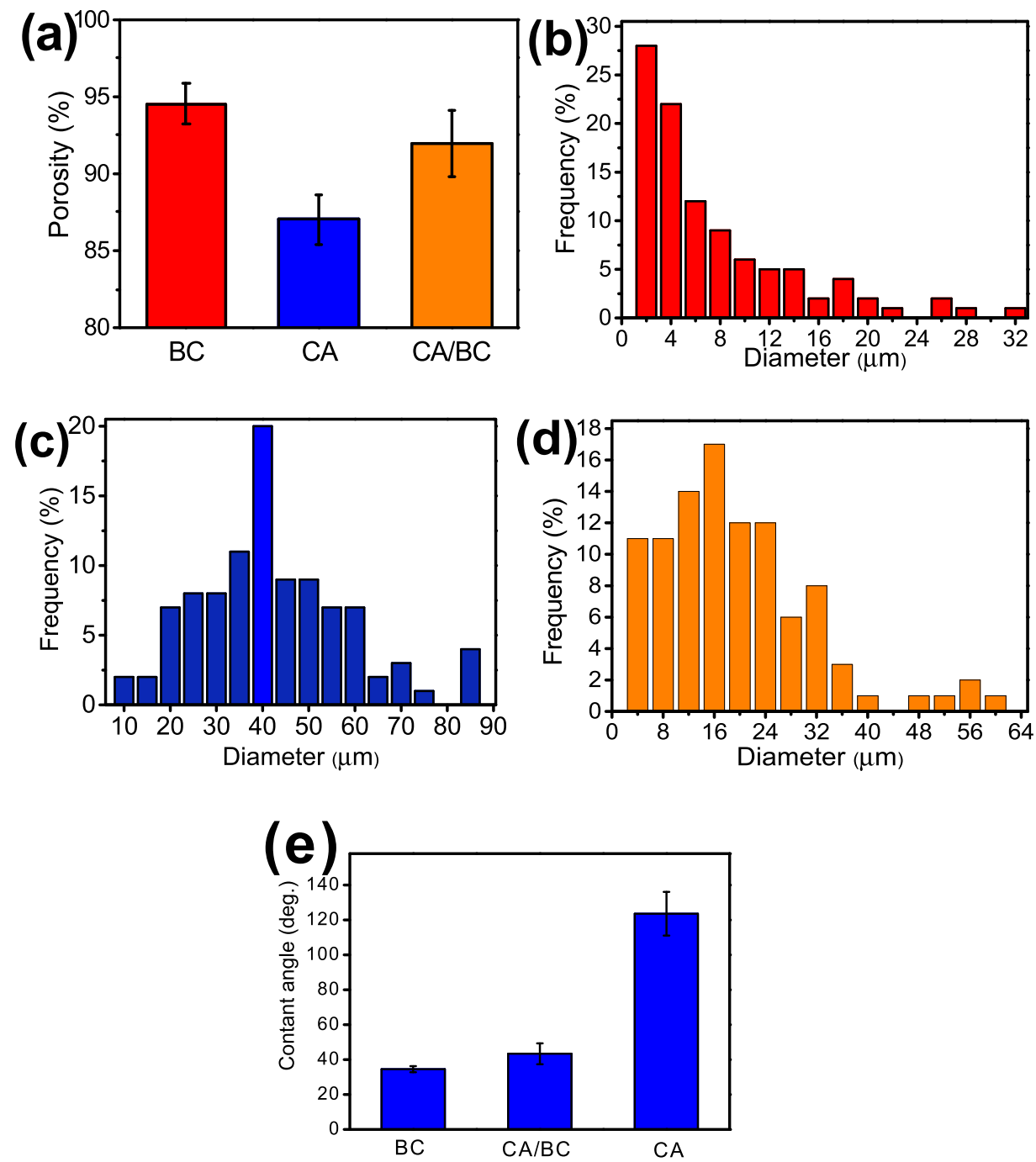

Fig. 2. (a) Porosities of BC, CA, and CA/BC scaffolds. (b-d) Pore size distribution of BC (b), CA (c) and CA/BC (d) scaffolds. (e) Water contact angles of BC, CA, and $\mathrm{CA} / \mathrm{BC}$ materials.

$\mathrm{NaOH}$ solution which leads to deacetylation of CA.

\subsection{Cell studies}

To compare the cell proliferation on $\mathrm{BC}$, CA, and CA/BC scaffolds, quantitative CCK8 assay was performed. Fig. 3 presents the absorbance as a function of culture time. It is found that MCF-7 cells cultured on

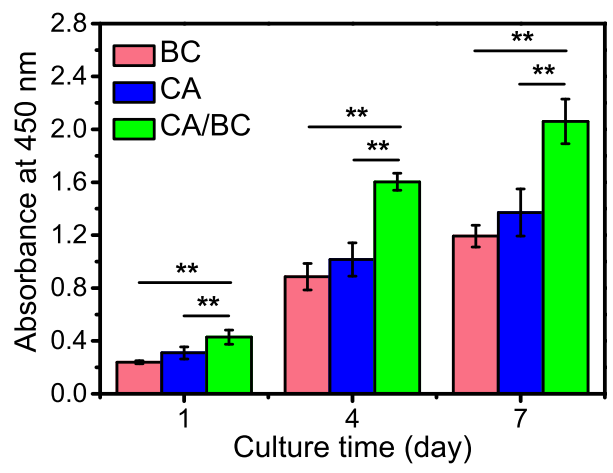

Fig. 3. Proliferation of MCF-7 cells cultured on BC, CA, and CA/BC scaffolds. The values are expressed as mean \pm SD. Significance was defined as $* p<0.05$ or $* * p<0.01 . \mathrm{n}=9$ in each group. each scaffold demonstrate robust proliferation during the incubation period of up to 7 days. Comparisons among them reveal a significantly higher absorbance of CA/BC than BC $(p<0.01)$ and CA $(p<0.01)$ scaffolds, which indicates that the nano-submicrofibrous structure of $\mathrm{CA} / \mathrm{BC}$ scaffold is more favorable for the proliferation of MCF-7 cells.

Cells are observed by fluorescent microscopy. As shown in Fig. 4, a progressive increase in the number of viable cells and size of cell aggregates over the experimental period of 7 days is observed. This suggests good biocompatibility of $\mathrm{BC}, \mathrm{CA}$, and $\mathrm{CA} / \mathrm{BC}$ scaffolds. It is clearly seen that more cells are observed on $\mathrm{CA} / \mathrm{BC}$ than $\mathrm{BC}$ and $\mathrm{CA}$ scaffolds at days 4 and 7, consistent with the CCK8 result.

Fluorescence microscopy was also used to observe the cell adherence after labeling the cytoskeletons with rhodamine phalloidin and the cell nuclei with DAPI (Fig. 5). Note that MCF-7 cells attach well on $\mathrm{BC}, \mathrm{CA}$, and $\mathrm{CA} / \mathrm{BC}$ scaffolds and formation of cell clusters is noted, suggesting that the three scaffolds can provide favorable microenvironment for growth and proliferation of MCF-7 cells. Similar to Figs. 4 and 5 shows larger cell clusters on CA/BC scaffold compared to $\mathrm{BC}$ or CA scaffold. In other words, the combination of BC nanofibers and CA submicrofibers greatly improves the cell compatibility compared to BC or CA scaffold, consistent with the CCK8 and live staining results.

To further observe the cell morphology, SEM observation was conducted after 4 and 7 days of culture. Fig. 6 reveals obvious time- 


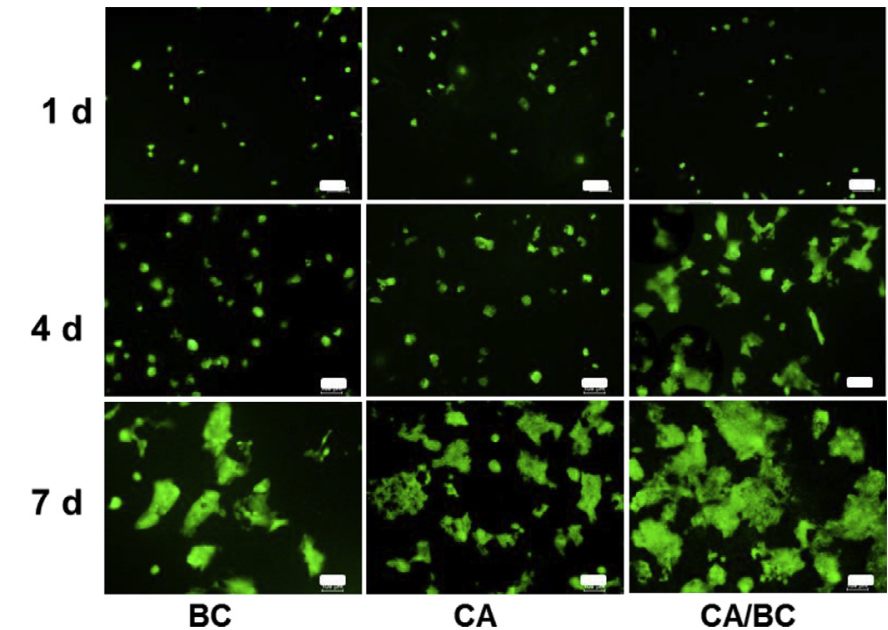

Fig. 4. Live staining micrographs of MCF-7 cells after 1, 4, and 7 days' culture on BC, CA, CA/BC scaffolds. Scale bar $=100 \mu \mathrm{m}$.

dependent cell cluster growth on each scaffold as well as formation of protrusions on CA and CA/BC scaffolds. Furthermore, CA/BC scaffold shows enhanced cell proliferation over BC or CA scaffold.

To determine the penetration of MCF-7 cells into the scaffolds, laser scanning confocal microscopy was used. As seen in Fig. 7, numerous cells are noted inside CA and CA/BC scaffolds while limited cells are inside the $\mathrm{BC}$ scaffold. Thus, in addition to providing a biomimetic architecture, the interpenetrated fiber system allows the 3D culture of cells, unlike the BC-only scaffold, which is not porous enough as to allow cell ingrowth, as shown in Fig. 2.

The antiproliferative effect of DOX on cancer cells seeded on different scaffolds is displayed in Fig. 8. The cytotoxic effect of DOX was monitored $24 \mathrm{~h}$ after drug addition. The MCF-7 cells on CA/BC scaffold are more resistant to DOX as compared to CA or BC scaffold, the cells grown on $\mathrm{BC}$ showing the least resistance. The higher resistance to DOX, which has been reported by many researchers for many types of cancer cells [34-36], suggests that cells grown on the CA/BC scaffold bear closer resemblance to in vivo microenvironment. It is believed that the structural architecture in the interpenetrated CA/BC scaffold increases cell-cell and cell-matrix interactions, which allowing the $3 \mathrm{D}$ proliferation, altogether contributing to drug resistance generation $[34,36,37]$. Therefore, the cultivation of cancer cells on CA/BC scaffold provides a better model for the evaluation of the cytotoxic effect of DOX.

Human cancer is a 3D structure consisting of ECM, neighboring cells, and blood vessels. It is accepted that the biophysical properties of ECM have a major impact on cancer cell survival, morphogenesis, invasion, and metastasis $[38,39]$. In recent years, more and more cancer biologists recognize the limitations of traditional 2D culture substrates like tissue culture polystyrene and glass in translating the conclusions of

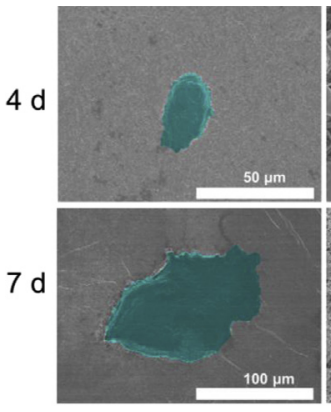

$\mathrm{BC}$

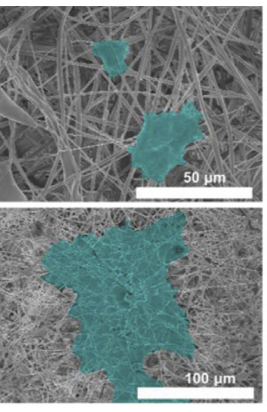

CA

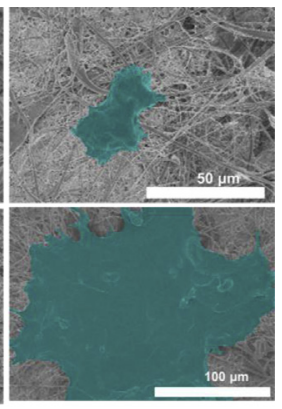

CA/BC
Fig. 6. SEM images of MCF-7 cells after 4 and 7 days of incubation on BC, CA, and $\mathrm{CA} / \mathrm{BC}$ scaffolds.

in vitro $2 \mathrm{D}$ studies to actual in vivo processes. Therefore, to mimic their surrounding environment, cancer cell culture on 3D scaffolds has attracted intensive research efforts [40-42]. However, little attention has been paid on the control of the accurate architecture of natural ECM. In a previous study, two types of poly( $\varepsilon$-caprolactone) (PCL) fiber mats with different orientations were fabricated by electrospinning technique to study the influence of contact cue guidance on breast cancer cell behavior [43]. However, no studies reported so far addressed the design of hierarchical structure of scaffolds. In this work, we have created a novel nano-submicrofibrous scaffold which is closer to natural ECM than single nanofibrous BC or submicrofibrous CA counterpart. Different cell attachment and proliferation are observed when MCF-7 cancer cells are cultured on scaffolds with different fiber structures. The cancer cells on the nano-submicrofibrous CA/BC scaffold show enhanced growth of clusters over single nanofibrous BC or submicrofibrous CA counterpart. This is understandable since according to the "contact guidance" theory, cells respond to the geometric cues by adjusting their cytoskeleton, and finally altering their gene and protein expressions $[43,44]$. Indeed, the porosities and wettability are different among $\mathrm{BC}, \mathrm{CA}$, and $\mathrm{CA} / \mathrm{BC}$ scaffolds. For example, BC is more hydrophilic than CA/BC while CA has more large pores than CA/BC. However, these competing factors mitigate the contributions of single $\mathrm{BC}$ and CA scaffolds to the promoted cancer cell behavior. Therefore, we believe that the biomimetic architecture of CA/BC scaffold plays a dominant role in enhancing the growth and proliferation of MCF-7 cells although future investigation is required to determine the accurate role of each parameter.

Interestingly, the preliminary drug sensitivity tests have proven that the cancer cells cultured on the nano-submicrofibrous CA/BC scaffold demonstrate significantly more resistance to DOX. Although it is not clear whether the hierarchical architecture can affect the cancer invasion and metastasis, our data has clearly demonstrated that the nanosubmicrofibrous CA/BC scaffold can directly control the chemsensitivity of cancer cells to drugs, which is critical in drug screening. Therefore, engineering a more biomimetic architecture of in vitro

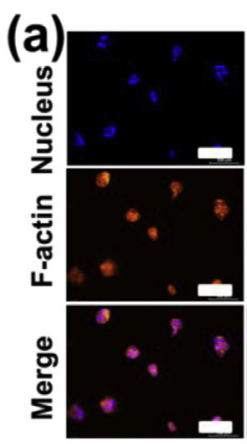

BC

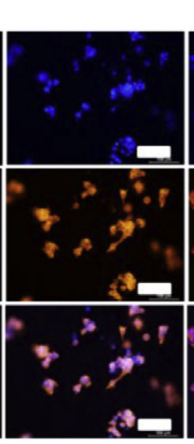

CA

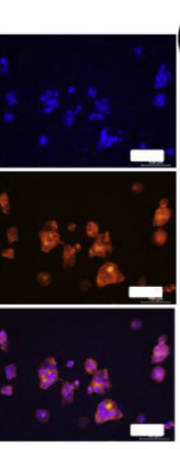

CA/BC

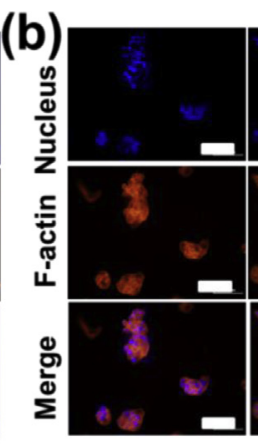

BC

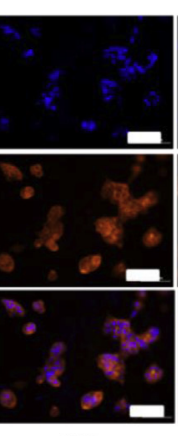

CA

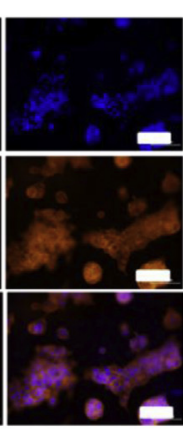

CA/BC
Fig. 5. Microscopic images of MCF-7 cells after proliferation for 4 (a) and 7 (b) days on BC, CA, and $\mathrm{CA} / \mathrm{BC}$ scaffolds. Fluorescent staining was performed with DAPI (blue, top row) and rhodamine phalloidin (red, middle row) for nuclei and cytoskeletons, respectively. The bottom row is the result of merging the top and middle rows (Scale bar $=100 \mu \mathrm{m}$ ). 

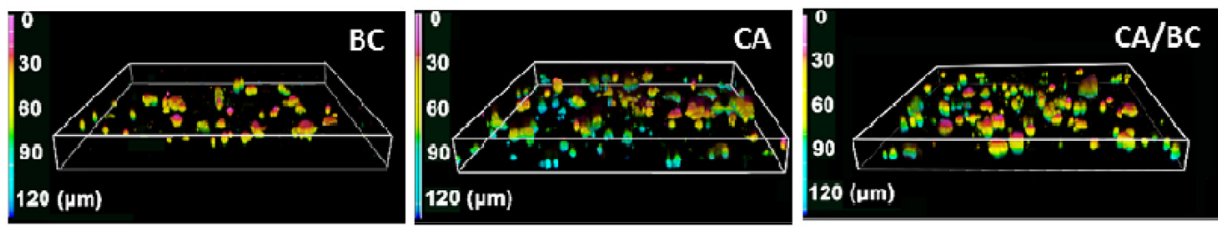

Fig. 7. Representative laser confocal microscopic images of MCF-7 cells after proliferation on BC, $\mathrm{CA}$, and CA/BC scaffolds for 4 days.

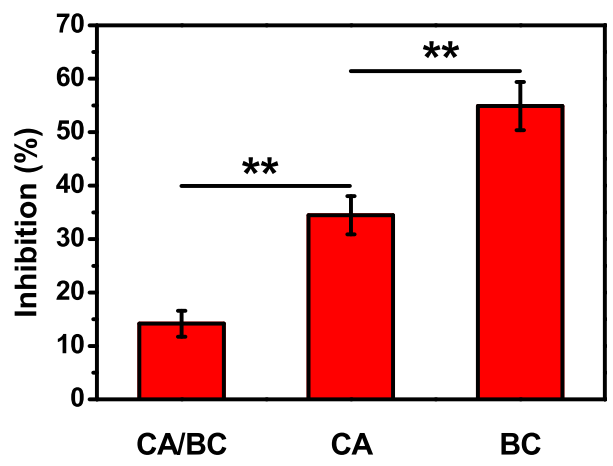

Fig. 8. Antiproliferative effect of DOX for MCF-7 cells cultured on BC, CA, and CA/BC scaffolds $24 \mathrm{~h}$ after DOX addition. ${ }^{*}, p<0.05 ;{ }^{* *}, p<0.01 ; \mathrm{n}=3$.

models is more effective for assessing the efficacy of anti-cancer drugs.

\section{Conclusions}

A novel nano/submicrofibrous CA/BC scaffold has been successfully fabricated by the combined electrospinning and modified in situ biosynthesis strategy. The BC fibers had an average diameter of $49 \mathrm{~nm}$ (close to the lower limit of natural collagen fibers) and the electrospun CA fibers showed an average diameter of $790 \mathrm{~nm}$ (comparable to the upper limit of natural collagen fibers). SEM observation revealed the close entanglement between $\mathrm{CA}$ and $\mathrm{BC}$ fibers, which led to improved mechanical properties of CA/BC scaffold over single BC or CA scaffold. More importantly, cell proliferation studies showed the greatest cell growth in the CA/BC scaffold among three scaffolds. Furthermore, SEM observation proved that the $\mathrm{CA} / \mathrm{BC}$ scaffold could promote the formation of cancer cell clusters, suggesting it is the most favorable microenvironment for growth and proliferation of MCF-7 cells. Finally, the cancer cells in the $\mathrm{CA} / \mathrm{BC}$ scaffold were less sensitive to the anticancer drug than single $\mathrm{CA}$ and $\mathrm{BC}$ scaffolds which makes it more promising for in vitro screening of anticancer drugs.

\section{Acknowledgements}

This work was supported by the Key Project of Natural Science Foundation of Jiangxi Province (Grant no. 20161ACB20018), the National Natural Science Foundation of China (Grant nos. 31870963, 31660264, and 51572187), the Youth Science Foundation of Jiangxi Province (Grant no. 20181BAB216010), and the Science and Technology Research Project of Jiangxi Education Department (Grant no. GJJ180348).

\section{Appendix A. Supplementary data}

Supplementary data to this article can be found online at https:// doi.org/10.1016/j.polymertesting.2019.106107.

\section{References}

[1] C. Wang, Z. Tang, Y. Zhao, R. Yao, L. Li, W. Sun, Three-dimensional in vitro cancer models: a short review, Biofabrication 6 (2014) 022001.

[2] Y. Jo, N. Choi, K. Kim, H.-J. Koo, J. Choi, H.N. Kim, Chemoresistance of cancer cells: requirements of tumor microenvironment-mimicking in vitro models in anti-cancer drug development, Theranostics 8 (2018) 5259-5275.
[3] M.M. Morgan, B.P. Johnson, M.K. Livingston, L.A. Schuler, E.T. Alarid, K.E. Sung, D.J. Beebe, Personalized in vitro cancer models to predict therapeutic response: challenges and a framework for improvement, Pharmacol. Ther. 165 (2016) 79-92.

[4] S. Pradhan, J.M. Clary, D. Seliktar, E.A. Lipke, A three-dimensional spheroidal cancer model based on PEG-fibrinogen hydrogel microspheres, Biomaterials 115 (2017) 141-154.

[5] M. Sheikholeslam, S.D. Wheeler, K.G. Duke, M. Marsden, M. Pritzker, P. Chen, Peptide and peptide-carbon nanotube hydrogels as scaffolds for tissue \& 3D tumor engineering, Acta Biomater. 69 (2018) 107-119.

[6] B.J. Gill, J.L. West, Modeling the tumor extracellular matrix: tissue engineering tools repurposed towards new frontiers in cancer biology, J. Biomech. 47 (2014) 1969-1978.

[7] S.K. Ranamukhaarachchi, R.N. Modi, A. Han, D.O. Velez, A. Kumar, A.J. Engler, S.I. Fraley, Macromolecular crowding tunes 3D collagen architecture and cell morphogenesis, Biomater. Sci. 7 (2019) 618-633.

[8] H. Luo, F. Gu, G. Xiong, D. Hu, Y. Zhu, Y. Wan, A multichanneled bacterial cellulose scaffold for 3D in vitro cancer culture, Cellul. Chem. Technol. 50 (2016) 49-56.

[9] H. Luo, G. Xiong, Y. Zhu, S.R. Raman, Y. Wan, Creation of macropores in threedimensional bacterial cellulose scaffold for potential cancer cell culture, Carbohydr. Polym. 114 (2014) 553-557.

[10] Y. Ikada, Challenges in tissue engineering, J. R. Soc. Interface 3 (2006) 589-601.

[11] J. Xie, M.R. MacEwan, X. Li, S.E. Sakiyama-Elbert, Y. Xia, Neurite outgrowth on nanofiber scaffolds with different orders, structures, and surface properties, ACS Nano 3 (2009) 1151-1159.

[12] E. Schnell, K. Klinkhammer, S. Balzer, G. Brook, D. Klee, P. Dalton, J. Mey, Guidance of glial cell. migration and axonal growth on electrospun nanofibers of poly-epsilon-caprolactone and a collagen/poly-epsilon-caprolactone blend, Biomaterials 28 (2007) 3012-3025.

[13] K. Tuzlakoglu, N. Bolgen, A.J. Salgado, M.E. Gomes, E. Piskin, R.L. Reis, Nano- and micro-fiber combined scaffolds: a new architecture for bone tissue engineering, J. Mater. Sci. Mater. Med. 16 (2005) 1099-1104.

[14] S. Deepthi, K. Jeevitha, M.N. Sundaram, K.P. Chennazhi, R. Jayakumar, Chitosan-hyaluronic acid hydrogel coated poly(caprolactone) multiscale bilayer scaffold for ligament regeneration, Chem. Eng. J. 260 (2015) 478-485.

[15] F.J. Bye, J. Bissoli, L. Black, A.J. Bullock, S. Puwanun, K. Moharamzadeh, G.C. Reilly, A.J. Ryan, S. Macneil, Development of bilayer and trilayer nanofibrous/ microfibrous scaffolds for regenerative medicine, Biomaterials Science 1 (2013) 942-951.

[16] S. Breslin, L. O'Driscoll, Three-dimensional cell culture: the missing link in drug discovery, Drug Discov, Today 18 (2013) 240-249.

[17] C. Fischbach, R. Chen, T. Matsumoto, T. Schmelzle, J.S. Brugge, P.J. Polverini, D.J. Mooney, Engineering tumors with 3D scaffolds, Nat. Methods 4 (2007) 855.

[18] C.M. Ghajar, M.J. Bissell, Tumor engineering: the other face of tissue engineering, Tissue Eng. A 16 (2010) 2153-2156.

[19] H. Luo, P. Xiong, J. Xie, Z. Yang, Y. Huang, J. Hu, Y. Wan, Y. Xu, Uniformly dispersed freestanding carbon nanofiber/graphene electrodes made by a scalable biological method for high-performance flexible supercapacitors, Adv. Funct. Mater. 28 (2018) 1803075.

[20] H. Luo, J. Dong, F. Yao, Z. Yang, W. Li, J. Wang, X. Xu, J. Hu, Y. Wan, Layer-byLayer assembled bacterial cellulose/graphene oxide hydrogels with extremely enhanced mechanical properties, Nano-Micro Lett. 10 (2018) 42.

[21] H. Luo, J. Dong, X. Xu, J. Wang, Z. Yang, Y. Wan, Exploring excellent dispersion of graphene nanosheets in three-dimensional bacterial cellulose for ultra-strong nanocomposite hydrogels, Composites Part A 109 (2018) 290-297.

[22] Y.Z. Wan, Y. Huang, C.D. Yuan, S. Raman, Y. Zhu, H.J. Jiang, F. He, C. Gao, Biomimetic synthesis of hydroxyapatite/bacterial cellulose nanocomposites for biomedical applications, Mater. Sci. Eng. C 27 (2007) 855-864.

[23] L. Hong, Y.L. Wang, S.R. Jia, Y. Huang, C. Gao, Y.Z. Wan, Hydroxyapatite/bacterial cellulose composites synthesized via a biomimetic route, Mater. Lett. 60 (2006) 1710-1713.

[24] G. Xiong, H. Luo, C. Zhang, Y. Zhu, Y. Wan, Enhanced biological behavior of bac terial cellulose scaffold by creation of macropores and surface immobilization of collagen, Macromol. Res. 23 (2015) 734-740.

[25] Y. Wan, Z. Yang, G. Xiong, R. Guo, Z. Liu, H. Luo, Anchoring Fe3O4 nanoparticles on three-dimensional carbon nanofibers toward flexible high-performance anodes for lithium-ion batteries, J. Power Sources 294 (2015) 414-419.

[26] Y. Wan, F. Zhang, C. Li, G. Xiong, Y. Zhu, H. Luo, Facile and scalable production of three-dimensional spherical carbonized bacterial cellulose/graphene nanocomposites with a honeycomb-like surface pattern as potential superior absorbents, J. Mater. Chem. 3 (2015) 24389-24396.

[27] Z. Wang, Y. Cui, J. Wang, X. Yang, Y. Wu, K. Wang, X. Gao, D. Li, Y. Li, X.-L. Zheng, Y. Zhu, D. Kong, Q. Zhao, The effect of thick fibers and large pores of electrospun poly( $\varepsilon$-caprolactone) vascular grafts on macrophage polarization and arterial regeneration, Biomaterials 35 (2014) 5700-5710.

[28] S. Grishanov, M. Tausif, S.J. Russell, Application of dynamic recursive splitting to 
estimate fibre entanglement in simulated nonwoven fibrous assemblies, Compos. Sci. Technol. 72 (2012) 1318-1323.

[29] S. Grishanov, M. Tausif, S.J. Russell, Characterisation of fibre entanglement in nonwoven fabrics based on knot theory, Compos. Sci. Technol. 72 (2012) 1331-1337.

[30] A. Kumar, K.M. Rao, S.S. Han, Development of sodium alginate-xanthan gum based nanocomposite scaffolds reinforced with cellulose nanocrystals and halloysite nanotubes, Polym. Test. 63 (2017) 214-225.

[31] V. Karageorgiou, D. Kaplan, Porosity of 3D biomaterial scaffolds and osteogenesis, Biomaterials 26 (2005) 5474-5491.

[32] N. Barnthip, A. Muakngam, Preparation of cellulose acetate nanofibers containing Centella asiatica extract by electrospinning process as the prototype of woundhealing materials, J. Bionanoscience 8 (2014) 313-318.

[33] N. Sultana, A. Zainal, Cellulose acetate electrospun nanofibrous membrane: fabrication, characterization, drug loading and antibacterial properties, Bull. Mater. Sci. 39 (2016) 337-343.

[34] C.J. Doillon, E. Gagnon, R. Paradis, M. Koutsilieris, Three-dimensional culture system as a model for studying cancer cell invasion capacity and anticancer drug sensitivity, Anticancer Res. 24 (2004) 2169-2178.

[35] C. Reyes-Moreno, A. Sourla, I. Chpki, C. Doillon, M. Koutsilieris, Osteoblast-derived survival factors protect PC-3 human prostate cancer cells from adriamycin apoptosis, Urology 52 (1998) 341-347.

[36] H.K. Dhiman, A.R. Ray, A.K. Panda, Three-dimensional chitosan scaffold-based
MCF-7 cell culture for the determination of the cytotoxicity of tamoxifen, Biomaterials 26 (2005) 979-986.

[37] W.S. Dalton, The tumor microenvironment as a determinant of drug response and resistance, Drug Resist. Updates 2 (1999) 285-288.

[38] H. Yu, J.K. Mouw, V.M. Weaver, Forcing form and function: biomechanical regulation of tumor evolution, Trends Cell Biol. 21 (2011) 47-56.

[39] H.K. Kleinman, D. Philp, M.P. Hoffman, Role of the extracellular matrix in morphogenesis, Curr. Opin. Biotechnol. 14 (2003) 526-532.

[40] P. Qiu, X. Qu, D.J. Brackett, M.R. Lerner, D. Li, C. Mao, Silica-based branched hollow microfibers as a biomimetic extracellular matrix for promoting tumor cell growth in vitro and in vivo, Adv. Mater. 25 (2013) 2492-2496.

[41] J. Kirshner, C.-J. Chen, P. Liu, J. Huang, J.E. Shively, CEACAM1-4S, a cell-cell adhesion molecule, mediates apoptosis and reverts mammary carcinoma cells to a normal morphogenic phenotype in a 3D culture, Proc. Natl. Acad. Sci. 100 (2003) $521-526$.

[42] L.F. Sempere, J.R. Gunn, M. Korc, A novel 3-dimensional culture system uncovers growth stimulatory actions by TGF $\beta$ in pancreatic cancer cells, Cancer Biol. Ther. 12 (2011) 198-207.

[43] S. Saha, X. Duan, L. Wu, P.-K. Lo, H. Chen, Q. Wang, Electrospun fibrous scaffolds promote breast cancer cell alignment and epithelial-mesenchymal transition, Langmuir 28 (2011) 2028-2034.

[44] C.D. Paul, P. Mistriotis, K. Konstantopoulos, Cancer cell motility: lessons from migration in confined spaces, Nat. Rev. Cancer 17 (2017) 131-140. 